This is the final peer-reviewed accepted manuscript of:

F.S.Romolo, E.Ferri, M.Mirasoli, M.D’Elia, L.Ripani, G.Peluso, R.Risoluti, E.Maiolini, S.Girotti. "Field detection capability of immunochemical assays during criminal investigations involving the use of TNT". Forensic Science International, 246, 25-30, 2015.

The final published version is available online at:

https://doi.org/10.1016/j.forsciint.2014.10.037

Rights / License:

The terms and conditions for the reuse of this version of the manuscript are specified in the publishing policy. For all terms of use and more information see the publisher's website.

This item was downloaded from IRIS Università di Bologna (https://cris.unibo.it/)

When citing, please refer to the published version. 


\section{Field detection capability of immunochemical assays during criminal investigations involving the use of TNT.}

Francesco Saverio ROMOLO ${ }^{1}$, Elida FERRI ${ }^{2}$, Mara MIRASOLI ${ }^{3}$, Marcello D’ELIA ${ }^{4}$, Luigi RIPANI ${ }^{5}$, Giuseppe PELUSO ${ }^{5}$, Roberta RISOLUTI ${ }^{6}$, Elisabetta MAIOLINI ${ }^{2}$, Stefano GIROTTI ${ }^{2}$

${ }^{1}$ Legal Medicine Section - SAIMLAL Department, SAPIENZA University of Rome, Viale Regina Elena, 336, 00161 Roma, Italy francescosaverio.romolo@uniromal.it and Institut de Police Scientifique, Université de Lausanne, Batiment Batochimie, CH-1015 Lausanne, Switzerland francescosaverio.romolo@ unil.ch

${ }^{2}$ Department of Pharmacy and Biotechnology, University of Bologna, Via San Donato 15, 40127 Bologna, Italy

${ }^{3}$ Department of Chemistry, University of Bologna, Via Selmi, 2, 40126 Bologna, Italy

${ }^{4}$ Emilia Romagna Regional Bureau of Scientific Police, Via Volto Santo 3, 40123 Bologna, Italy

${ }^{5}$ Scientific Investigation Unit, Carabinieri Roma, Viale Tor di Quinto, 151, 00191 Roma, Italy

${ }^{6}$ Department of Chemistry, SAPIENZA University of Rome, Piazzale Aldo Moro 5, 00185 Roma, Italy

Corresponding Author: Francesco Saverio Romolo: francescosaverio.romolo@uniromal.it or francescosaverio.romolo@unil.ch 


\section{Abstract}

The capability to collect timely information about the substances employed on-site at a crime scene is of fundamental importance during scientific investigations in crimes involving the use of explosives. TNT (2,4,6-trinitrotoluene) is one of the most employed explosives in the $20^{\text {th }}$ century and despite the growing use of improvised explosives, its use by criminals having access to TNT is not expected to decrease. Immunoassays are simple and selective analytical tests able to detect molecules and their immunoreactions canoccur in portable formats for use on-site. This work demonstrates the application to typical forensic samples from experimental tests of three immunochemical assays able to detect TNT: an indirect competitive ELISA with chemiluminescent detection (CL-ELISA), a colorimetric lateral flow immunoassay (LFIA) based on colloidal gold nanoparticles label, and a chemiluminescent-LFIA (CL-LFIA). Under optimised working conditions, the LOD of the colorimetric LFIA was $1 \mu \mathrm{g} \mathrm{mL}^{-1}$ and of CL-LFIA was 0.05 $\mu \mathrm{g} \mathrm{mL} \mathrm{m}^{-1}$. The total analysis time for LFIAs was 15 minutes. ELISA proved to be a very good laboratory approach, showing very good sensitivity (LOD of $0.4 \mathrm{ng} \mathrm{mL}^{-1}$ ) and good reproducibility (CV value about $7 \%)$.

The samples tested included various materials involved in controlled explosions of Improvised Explosive Devices (IEDs) and samples collected from hand swabbing after TNT handling tests. In the first group of tests, targets covered with six different materials (metal, plastic, cardboard, carpet fabric, wood and adhesive tape) were fixed on top of wooden poles (180 cm high). Samples of soil from the explosion area and from the different material covering the targets were collected after each explosion and analysed. The second group of tests included volunteers simulating the manipulation of small charges of TNT followed by hand swabbing at different times, with and without washing.

Results confirmed that immunoassays were suitable to detect post-blast residues in soil and target materials and post transfer residues on hands. Results from ELISA were consistently in good agreement with results by LFIAs and were confirmed by gas chromatography coupled to mass spectrometry (GC-MS). The reported immunoassays data demonstrate the suitability of LFIAs as on-site rapid and effective assays to detect TNT traces and the utility of CL-ELISA to obtain very sensitive detection in forensic investigations and testing, with CL-LFIA having performances in between LFIA and CL-ELISA.

Keywords: 2,4,6-trinitrotoluene (TNT), explosives, chemiluminescence, ELISA, LFIA, on-site tests, crime scene, swabbing. 


\section{Introduction}

Forensic analytical procedures generally start with a sampling step. In bombing-scene investigations, it is important to provide valuable information to the investigators by collecting the material that is most likely to produce evidence [1]. 2,4,6-trinitrotoluene (TNT) is a very effective and relatively safe explosive because of its high explosive power, high chemical stability and low sensitivity to impact and friction [2, 3]. Royds et al. described very well the investigations after the Bali bombings, where the explosion of three charges containing TNT killed two hundred and two people [1]. The approach taken in that occasion was to analyse debris in a mobile laboratory starting with a number of presumptive tests (including $3 \% \mathrm{KOH}$ in ethanol) and ion mobility spectrometry (IMS). Another good example of the need for on-site testing for explosive traces concerns the forensic activities after the bombings in Florence, Rome, and Milan in 1993. TNT was found in samples from all five bombing scenes. Mobile explosives detectors, similar to those used in airports to detect hidden explosives, gave fast preliminary results of samples from places where explosive charges were prepared and from vehicles used to transport them. Places and vehicles were suggested by suspects who decided to collaborate to the inquiry and positive results supported their credibility [4]. Another forensic application warranting fast and sensitive detecting capability is the analysis of samples from people suspected of recently handling explosives.

Since the first studies published in the 1960s, several procedures for laboratory analysis of postexplosion residues and traces on suspects or their belongings were developed [5,6]. For example, soil samples from an explosion crater can be extracted by solvent [7], and surfaces can be sampled by swabbing [8], tape lifting [9] or vacuum lifting [10]. General and comprehensive schemes for the analysis of postexplosion residues where first described in 1970s. They can include the team approach for processing the bomb-scene, the visual examination of debris, and the sample preparation and analysis [11]. Gas chromatography (GC) coupled to Thermal Energy Analyzer (TEA) was introduced in 1975 [12] and resulted in very selective and sensitive analysis of nitrocompounds [13, 14]. The introduction of tandem mass spectrometry (MS) permitted more selective procedures for forensic identification of explosives [15-21]. All of the laboratory techniques listed above are included in effective but time consuming procedures and must be coupled with tests that have good on-site detection capability, allowing selection of materials that are most likely to later produce evidence during laboratory analysis [22]. There are also field tests for TNT based on the formation of coloured Meisenheimer and Janowsky anions in alkaline acetone or methanol [23, 24]. This approach stemmed from procedures based on color changes to those based on fluorescence emission [25] or on optical chemosensing [26], but the use of biologically inspired systems generally resulted in procedures with the best selectivity [27, 28].

The use of the antibodies in analytical methods can help to achieve the good detection capability needed for forensic applications, especially on-site. Competitive immunoassays have been used to detect many types of small molecules including explosives such as TNT [27, 29]. Three tests were recently developed to detect TNT: an indirect competitive enzyme-linked immunosorbent assay with chemiluminescent detection (CLELISA) [30] and two lateral flow immunoassays (LFIAs) particularly suitable for on-site use, the first based 
on colloidal gold nanoparticles label (colorimetric detection) [30] and the other based on chemiluminescent label detection [31].

This work describes the application of these three immunoassays for the detection TNT traces in typical forensic samples such as samples from an explosion test site and post-handling hand swabs. The aim was to evaluate and compare the effectiveness of these tests to give timely forensic information and to contribute to criminal investigation in the early stage.

\section{Materials and Methods}

\section{Explosion tests}

Explosion tests were carried out in civil and military firing areas in Italy (a quarry near Castel S.Pietro, Bologna, and an army facility near Casal Borsetti, Ravenna) by one bomb squad of the Italian State Police in collaboration with specialists of the Scientific Police of Bologna. Targets of $100 \mathrm{~cm}^{2}$ each (see Fig.1) covered with different materials (metal, plastic, cardboard, carpet fabric) were fixed at the top of a wooden pole (180 cm high) with adhesive tape and placed at different positions around the explosion point.

A first set of controlled explosions was carried out using TNT charges of $34 \mathrm{~g}, 67 \mathrm{~g}$, and $100 \mathrm{~g}$ to study the feasibility of experimental arrangements. In each single test, nine poles with targets were placed around the charge at $1.5 \mathrm{~m}, 9 \mathrm{~m}$ and $15 \mathrm{~m}$ from the explosion point (Fig. 2A). Meteorological parameters were recorded using a WS-2300 European Wired/Wireless Weather Center. Temperature was between $+30^{\circ} \mathrm{C}$ and $+34^{\circ} \mathrm{C}$ and wind speed was less than $10 \mathrm{~km} / \mathrm{h}$ from N/NW.

Further experiments in conditions more representative of real criminal events were carried out with a charge of $1 \mathrm{~kg}$ of TNT, surrounded by six target poles placed at $3 \mathrm{~m}$ and $6 \mathrm{~m}$ from the explosion site (Fig. 2B), and with a charge of $2 \mathrm{~kg}$ surrounded by nine target poles placed at $3 \mathrm{~m}, 6 \mathrm{~m}$, and $9 \mathrm{~m}$ from the explosion site (Fig. 2C). The recorded parameters were: $991.5 \mathrm{hPa}$ pressure, temperature between $-1{ }^{\circ} \mathrm{C}$ and $+4^{\circ} \mathrm{C}, 90 \%$ humidity and $10-20 \mathrm{~km} / \mathrm{h} \mathrm{W} / \mathrm{NW}$ wind speed and direction.

For charges up to $1 \mathrm{~kg}$ TNT, one blasting cap N.8 was used; for the test with a charge of $2 \mathrm{~kg}$ TNT, two blasting caps N.8 were used.

\section{Handling tests}

Handling tests were carried out by three volunteers. Blank samples were taken from their hands before each test. A small block (about $10 \mathrm{~g}$ ) of military TNT was handled by each person for 3-5 min, simulating its positioning on a working surface. Four swabbing experiments were carried out: sampling immediately after handling, sampling immediately after handling and washing hands only with water, sampling immediately after handling and washing hands with water and soap, sampling two hours after handling. 


\section{Sample collection and treatment}

Soil samples were collected in the explosion area (the explosion point and the area delimited by the targets) using a metal spatula and stored in plastic vials with screw cap at room temperature (RT). TNT residues were extracted by adding $500 \mu \mathrm{L}$ of methanol to $0.4 \mathrm{~g}$ of soil and shaking for 3 minutes. Methanol was separated by centrifugation [30].

Samples from surfaces (targets and hands) were collected by swabs. Two different swabbing systems were tested. The swabs of the first type were cotton buds from ARTSANA (Grandate, Como, Italy) wetted with methanol RS for HPLC from Carlo Erba (Milano, Italy). Samples were collected from different portions of each area of the targets using the cotton buds wetted with methanol. Each swab was then dipped in $500 \mu \mathrm{L}$ of methanol in a glass vial with screw cap. The extraction of the explosive residues collected by swabs was obtained by shaking the vials for 3 minutes.

For handling tests, the swabs were prepared using round cotton pads from Fort James Italia (Genova, Italy) cut in four, wetted with isopropyl alcohol (propan-2-ol) RS for HPLC from Carlo Erba (Milano, Italy), already successfully tested for several explosives, included TNT [32], TATP [33] and organic gunshot residue [34]. Swabs were dampened with $0.4 \mathrm{~mL}$ isopropyl alcohol (propan-2-ol) and then shaken to remove the excess solvent. The swab was firmly rubbed numerous times over the entire surface of both hands of each subject: palm, fingers, thumb, back and wrist. Three consecutive swabs were used to sample each subject. After sampling, each swab was immediately enclosed into a small glass jar (NEMI $15 \mathrm{~mL}$ ) with screw cap (Eurovetrocap Milano, Italy) and sealed with Parafilm ${ }^{\circledR}$ M (Pechiney Plastic Packaging Company, Menasha, WI, USA). Samples were stored at $-20^{\circ} \mathrm{C}$ before analysis. After adding $0.1 \mathrm{~mL}$ of propan-2-ol, swabs were treated in an ultrasonic bath (FALC Instruments, Bergamo, Italy) for 15 minutes. The swab was then removed and squeezed (to capture the maximum amount of solution in the glass vial) and the solution was filtered on $0.2 \mu \mathrm{m}$ OlimPeak nylon filters (Teknokroma, Sant Cugat del Vallés, Barcelona, Spain) and evaporated under a nitrogen flux. A solution of musk xylene in acetonitrile (Analytical Standard Fluka) purchased from Sigma Aldrich (Milano, Italy) was used as internal standard after diluting with propan-2-ol. Both solutions (in acetonitrile and dilution in propan-2-ol) were stored at $2^{\circ} \mathrm{C}$. An internal standard of 100 $\mu \mathrm{L}$ of propan-2-ol containing musk xylene $5 \mathrm{mg} / \mathrm{L}$ was added before GC-MS analysis. The extraction procedure was repeated three times for each swab to obtain three fractions.

\section{Immunoassays}

Chemiluminescent ELISA, (CL-ELISA). CL-ELISA was performed according to [30] in 96-well microplates as an indirect competitive format. Briefly: the microplate was coated before use with $1 \mu \mathrm{g} \mathrm{mL} \mathrm{m}^{-1} \mathrm{TNB}-\mathrm{OVA}$ conjugate in $0.05 \mathrm{~mol} \mathrm{~L}-1$ carbonate-bicarbonate buffer, $\mathrm{pH} 9.6$ (100 $\mu \mathrm{L} /$ well) and incubated overnight at Room Temperature (RT). After washing, $50 \mu \mathrm{L} /$ well of 1:40,000 dilution of antiserum in phosphate buffer (PBSG; 10 mmol L ${ }^{-1}$ pH 7.4; 137 mmol L ${ }^{-1} \mathrm{NaCl}, 2.7$ mmol L ${ }^{-1} \mathrm{KCl}, 10 \mathrm{mmol} \mathrm{L}{ }^{-1} \mathrm{Na}_{2} \mathrm{HPO}_{4}, 2 \mathrm{mmol} \mathrm{L}^{-1}$ $\mathrm{KH}_{2} \mathrm{PO}_{4}, 0.5 \%$ fish gelatine) and $50 \mu \mathrm{L} /$ well standard solutions or sample extracts were added and incubated 
for $1 \mathrm{~h}$ at RT. Each extract solution was split into three wells; each standard solution was split into six wells. The standard solution of TNT was purchased from AccuStandard (New Haven, USA). Methanol was RS for HPLC from Carlo Erba (Milano, Italy). All other chemicals and organic solvents were reagent grade.

The microplate was washed and $100 \mu \mathrm{L} /$ well goat antimouse IgG-HRP diluted 1:2000 in PBSG (according to the manufacturer's guidelines) was added before incubating for 90 minutes at RT. Ultimately, after washing, $100 \mu \mathrm{L}$ of luminescent mixture $\left(45 \mu \mathrm{L}\right.$ luminol $1 \mathrm{mmol} \mathrm{L}^{-1} ; 10 \mu \mathrm{L}$ p-iodophenol $0.5 \mathrm{mmol} \mathrm{L}^{-1}$ both from Sigma, Hamburg, Germany), $9845 \mu \mathrm{L}$ borate buffer $\left(0.2 \mathrm{~mol} \mathrm{~L}{ }^{-1}, \mathrm{pH} 8.5\right.$; $50 \mathrm{mmol} \mathrm{L}^{-1}$ $\mathrm{Na}_{2} \mathrm{~B}_{4} \mathrm{O}_{7} .10 \mathrm{H} 2 \mathrm{O} ; 200 \mathrm{mmol} \mathrm{L}-1 \mathrm{H}_{3} \mathrm{BO}_{3}$ ) and $100 \mu \mathrm{L}$ of $1 \mathrm{mmol} \mathrm{L}^{-1}$ hydrogen peroxide (Merck, Germany) were added to each well and the absorbance at $425 \mathrm{~nm}$ was immediately recorded by means of a Victor 1420 luminometer (Wallac-Perkin-Elmer, Waltham, MA, USA). Four readings per well were recorded. The chemiluminescent data, expressed as relative luminescent units (RLU) were normalized according to the expression:

$$
\% \mathrm{~B} / \mathrm{B}_{0}=100\left(\mathrm{~A}-\mathrm{A}_{\text {excess }}\right) /\left(\mathrm{A}_{0}-\mathrm{A}_{\text {excess }}\right)
$$

and mathematically fit to a four-parameter logistic equation using SigmaPlot Version 8.0. LOD was calculated in correspondence of the RLU value obtained according to the expression:

$R L U_{L O D}=\left(A_{0}-A_{\text {excess }}\right) \times 0.9+A_{\text {excess }}$

The CL-ELISA showed very good sensitivity (LOD of $0.4 \mathrm{ng} \mathrm{mL}^{-1}$ ) and good reproducibility (CV value about 7\%) [30].

Colorimetric lateral flow immunoassay, (LFIA). LFIA was prepared according to Girotti et al. [30]. The lateral-flow assay was performed by dipping the strips in a well containing $50 \mu \mathrm{L}$ running buffer (PBS 1X-1\% BSA), $10 \mu \mathrm{L}$ rabbit anti mouse-colloidal gold, and $3 \mu \mathrm{L}$ mouse anti-TNT antibody. The upper part of the strip was in contact with a piece of filter paper, which forced complete migration of the liquid throughout the membrane. After 5 minutes, two visible red lines confirmed the assay had been conducted correctly on a sample not containing TNT (Fig. 3). The sample extracts were added into the well containing the reagents described above. The presence of the analyte was revealed by the colour intensity decrease of the test line, directly proportional to the amount of analyte in the sample, until its complete disappearance. The colorimetric LFIA showed to be very selective in cross reactivity studies with a LOD of $1 \mu \mathrm{g} \mathrm{mL}^{-1}$ [30].

Chemiluminescent lateral flow immunoassay, (CL-LFIA). CL-LFIA was performed according to [31], using nitrocellulose LFIA strips. The assay was performed by dipping the LFIA strip in a microtiter plate well containing $50 \mu \mathrm{L}$ of running phosphate buffer (PBS; $10 \mathrm{mmol} \mathrm{L}^{-1}, \mathrm{pH} 7.4 ; 137 \mathrm{mmol} \mathrm{L}^{-1} \mathrm{NaCl}, 2.7$ mmol L ${ }^{-1} \mathrm{KCl}, 10 \mathrm{mmol} \mathrm{L}{ }^{-1} \mathrm{Na}_{2} \mathrm{HPO}_{4}, 2$ mmol L ${ }^{-1} \mathrm{KH}_{2} \mathrm{PO}_{4}$, with 3\%, w/v BSA, 1:1000, v/v anti-TNT mouse antibody, and 1:20,000, v/v anti-mouse HRP-labelled rabbit antibody) and $1 \mu \mathrm{L}$ of sample (or TNT standard solution for generating calibration curves in the range between 0.02 and $5 \mu \mathrm{g} \mathrm{mL}^{-1}$ ). When flow through the membrane ended (about $10 \mathrm{~min}$ ), $50 \mu \mathrm{L}$ of HRP luminol-based CL substrate was dispensed in the well and flowed for 3 minutes. The strip was then transferred in the portable imaging device and the CL image was acquired using an integration time of 5 seconds. During the acquisition, the CCD sensor temperature was fixed at $-10{ }^{\circ} \mathrm{C}$. The imaging system was based on a CCD camera (model MZ-2PRO, 
MagZero, Pordenone, Italy) equipped with a thermoelectrically cooled monochrome CCD image sensor, coupled with a Computar 2/3 in. $8 \mathrm{~mm}, \mathrm{f} 1.4$ objective (CBC Corp., Commack, NY, USA), and connected to a light-tight dark box to image LFIA strips without interference from ambient light [31]. The camera was controlled by a laptop computer powered by a $12 \mathrm{~V}$ battery to allow portability of the imaging system. Images were recorded in the Flexible Image Transport System format and analysed using the WinLight 32 Version 2.91 (Berthold Technologies GmbH \& Co. KG, Bad Wildbad, Germany). The reference instrument was a research-grade luminograph (NightOWL LB 981, Berthold Technologies GmbH \& Co. KG) equipped with a back-illuminated thermoelectrically cooled CCD camera.

For quantitative analysis, the CL signal was measured in the LFIA membrane areas corresponding to the analytical and control lines, as well as in two couples of adjacent areas that were used to evaluate the CL background signal of each line. The calibration curve was obtained by plotting the fraction of bound antiTNT antibody displaced versus TNT concentration, then performing a non-linear regression with a fourparameter logistic equation using GraphPad Prism Version 5.03 (GraphPad Software, San Diego, CA). The limit of detection of the CL-LFIA was $0.05 \mu \mathrm{g} \mathrm{mL}{ }^{-1}$, requiring 15 minutes for analysis [31].

\section{Quantitative analysis by GC-MS}

All samples were analysed via a GC-MS developed for this purpose as the reference method to obtain forensic confirmation and quantitative results to be compared to the results obtained by immunoassays.

A gas chromatograph (Agilent Technologies 7890) equipped with a mass spectrometer (Agilent Technologies 5975C MSD) used in electron impact ionisation mode and an autosampler (Agilent Technologies 5973 B) was employed. The software was Agilent Chemstation. The injector was a multi mode injector and operated in split mode (5:1). A fused-silica capillary column (Agilent 19091S-433HP-5MS) with chemically bonded phase 5\% phenyl-95\% dimethylpolysiloxane $10 \mathrm{~m}$ x $250 \mu \mathrm{m}$ i.d., $0.25 \mu \mathrm{m}$ film thickness was used. Conditions were as follows: injection volume, $1 \mu \mathrm{L}$; injection port temperature, $175^{\circ} \mathrm{C}$; carrier gas, helium 99,9995\% purity; flow $1 \mathrm{~mL} \mathrm{~min}^{-1}$; column temperature, $50^{\circ} \mathrm{C}$ for $2 \mathrm{~min}$; then programmed $25^{\circ} \mathrm{C} / \mathrm{min}$ to $200^{\circ} \mathrm{C}$ for 3 minutes, after post-run at $250^{\circ} \mathrm{C}$ for 5 minutes; transfer line temperature, $200^{\circ} \mathrm{C}$. The damping gas was helium 99,9995\% purity; flow 0,3 mL min-1; the source was set at $200^{\circ} \mathrm{C}$; the scan range of the mass spectrometer was between $\mathrm{m} \mathrm{z}^{-1} 35$ and 350 .

The GC-MS method reached a LOD of $0,4 \mu \mathrm{g} \mathrm{mL} \mathrm{m}^{-1}$ and a LOQ of $0,8 \mu \mathrm{g} \mathrm{mL} \mathrm{m}^{-1}$. Linearity of the response was tested in the range $1-10 \mu \mathrm{g} \mathrm{mL}-1$ obtaining the following calibration curve: $\mathrm{y}=0.5606 \mathrm{x}$ $0.0922, \mathrm{r}^{2}=0.9851$ and in the range $10-100 \mu \mathrm{g} \mathrm{mL}-1$ obtaining: $\mathrm{y}=0.8583 \mathrm{x}-0.4536, \mathrm{r}^{2}=0.9984$. The intraday coefficient of variation $(\mathrm{CV})$ was $1 \%$ and the inter-days CVRS was $8 \%$, both at $1 \mu \mathrm{g} \mathrm{mL} \mathrm{m}^{-1}$. The accuracy was $10 \%$ at $1 \mu \mathrm{g} \mathrm{mL}^{-1}$.

\section{Results and discussion}

\section{Explosion tests}


Preliminary tests performed using the smaller charges of TNT (34 and $67 \mathrm{~g}$ ) showed that traces can be revealed by CL-ELISA and GC-MS only in the soil samples from craters and then larger charges were employed. Samples from the targets and the soil after the explosion of the $100 \mathrm{~g}$ TNT charge were analysed by colorimetric LFIA, CL-ELISA and GC-MS. After this test, only the swabs used on some materials of target placed at $1 \mathrm{~m}$ from the detonation site and in the direction along which the explosion cloud was moved by the wind (target 3 ) tested positive. The soil sample taken close to the pole of that target also resulted positive to TNT residues. All the remaining target and soil samples were negative. LFIA gave clearly positive results for the swabs used on the adhesive tape and the carpet fabric. The samples from plexiglass, wood, and soil were classified as positive (Fig. 3). These results were confirmed by CL-ELISA and GC-MS. Both assays gave positive results for all the same samples from target 3 and for soil. The quantitative values from CL-ELISA and GC-MS were in good agreement (Table 1).

These findings suggested planning new tests with larger charges to be performed in a suitable military area. The detonation of a $1 \mathrm{~kg}$ TNT charge was planned; post-explosion samples were all analysed by LFIA, CL-ELISA and GC-MS. Results are reported in Table 2.

In this case, all targets from the inner circle ( $3 \mathrm{~m}$ far from the charge) and the soil taken close to the pole of target $n .1$ gave positive results. The quantitative data shown in Table 2 confirm good agreement between the CL-ELISA and GC-MS determination.

A further explosion test was performed by employing a $2 \mathrm{~kg}$ charge and a higher number of targets. Sample extracts were tested by all four methods. Data obtained by CL-LFIA, CL-ELISA and GC-MS analyses are reported in Table 3. All samples positive to the other assays were confirmed by the colorimetric LFIA. Again, only the targets placed in the inner circle ( $3 \mathrm{~m}$ from the exploding TNT charge) were contaminated by the explosion residues. The soil samples taken close to the poles of the targets 7 and 8 contained TNT residues. All remaining soil samples resulted negative to all analytical methods here employed.

It is interesting to observe the good agreement between the CL-LFIA and GC data. With only one exception, the two values obtained are very similar, underlining the capability of this rapid and simple test to assess the presence and amount of the analyte with acceptable accuracy. 


\section{Handling tests}

During handling tests, the TNT sample was manipulated for about 3-5 min by the three volunteers (A, B and C). The four different experiments were Handling Test 1 (HT1): samplings were carried out immediately after handling; Handling Test 2 (HT2): sampling immediately after handling and washing the hands with water but without soap; Handling Test 3 (HT3): sampling immediately after handling and washing the hands with water and soap; Handling Test 4 (HT4): sampling was performed two hours after handling, without washing. The swab extracts were analysed separately by CL-ELISA, LFIA and GC-MS as done before in case of explosion test sample. The results obtained in handling tests are reported in Table 4.

As expected, the amounts of TNT residue determined immediately after handling were much larger than in samples from the explosion tests. In spite of the great differences among the residue amounts in HT1 positive samples, all of them resulted positive to LFIA. In a typical forensic context, one swab is used for sampling both hands, or maximum one swab per hand. According to these data, a single swab is expected to result clearly positive to LFIA if sampling occurs early after handling TNT.

The TNT residues collected by the swabs in HT2 were very low compared to the results of HT1. At least one of the samples was recognized as positive by all the three method of analysis, confirming their fitness for purpose in forensic application. The results obtained from analysis of the HT3 swabs were practically the same results obtained from the HT2 test, concluding that the use of soap during hand washing does not have significant influence on the removal of TNT residues. Only two subjects were swabbed in HT4. The first swab (taken two hours after handling the TNT residues) from Subject A contained about 20 $\mu \mathrm{g} \mathrm{mL} L^{-1}$, while the first swab from Subject B was close to the results obtained after washing tests. The responses of the three assays were still in agreement.

The reported results show that the tested immunoassays are useful forensic tools to obtain fast detection of TNT presence at a bombing scene or on the hands of suspects during criminal investigations and accurate quantitative data.

\section{Conclusions}

The preliminary results obtained during this research support the importance of portable tests for a most effective selection of the material to collect for further analytical work in places where explosive charges were used or prepared, or in vehicles used to transport an IED. The LFIA is particularly promising because it is the fastest, it is easy-to-use, portable and the cheapest technique, which also produced results continuously in agreement with reference methods such as GC-MS. Further research is needed; however, the 
results obtained by CL-LFIA and CL-ELISA (more sensitive) showed to be sensitive, selective and accurate enough to be used in forensic procedures. These procedures can be very useful to select the samples needing forensic confirmation by more expensive and time consuming procedures. Because only samples testing positive to immunoassays are analysed for confirmation, this approach saves time and money as well as produces faster results, consequentially resulting in optimisation of resources. These traits are always desirable in criminal investigations. The authors believe the reported results show the fitness for purpose of LFIA, CL-LFIA and CL-ELISA in forensic analytical approaches used to seek TNT traces. Results confirmed that immunoassays were suitable to detect post-blast residues in soil and target materials and post transfer residues on hands. Results from ELISA were consistently in good agreement with results by LFIAs and repeatedly confirmed by GC-MS. The reported immunoassays data demonstrate the suitability of LFIAs as on-site rapid and effective assays to detect TNT traces and the utility of CL-ELISA to obtain very sensitive detection in forensic investigations and testing, with CL-LFIA having performances in between LFIA and CL-ELISA.

\section{References}

[1] D. Royds, S.W. Lewis, A.M. Taylor, A case study in forensic chemistry: The Bali bombings, Talanta 67 (2005) 262-268.

[2] R. Meyer, J., A. Homburg, Explosives. Sixth Edition WILEY-VCH Verlag GmbH \& Co. 2007.

[3] T. Urbanski, Chemistry and Technology of Explosives, Vol. I, p. 265, Pergamon Press, Oxford, 1964.

[4] F.S. Romolo, Forensic analytical chemistry of explosives and organic gunshot residue. Proceedings of the $9^{\text {th }}$ International Symposium on Analysis and Detection of Explosives (ISADE) and $4^{\text {th }}$ Forensic International Network for Explosives Investigation (FINEX), held in Paris (F), July 2 to 6 (2007), 271 277.

[5] J. Yinon, S. Zitrin, The Analysis of Explosives, Pergamon Press, Oxford, 1981.

[6] J. Yinon, S. Zitrin, Modern methods and applications in analysis of explosives, John Wiley \& Sons, Chichester, 1993.

[7] A. Choodum, P. Kanatharana, W. Wongniramaikul, N. NicDaeid, Rapid quantitative colourimetric tests for trinitrotoluene (TNT) in soil, Forensic Sci. Int. 222 (2012) 340-345.

[8] N. Song-im, S. Benson, C. Lennard, Evaluation of different sampling media for their potential use as a combined swab for the collection of both organic and inorganic explosive residues, Forensic Sci. Int. 222 (2012) 102-110.

[9] A. Zeichner, S. Abramovich-Bar, T. Tamiri, J. Almog, A feasibility study on the use of double-sided adhesive coated stubs for sampling of explosive traces from hands. Forensic Sci. Int. 184 (2009) 42-46.

[10] J.S. Wallace, W.J. McKeown, Sampling procedures for firearms and/or explosives residues, J. Forensic Sci. Soc. 33 (1993) 107-116

[11] A. Beveridge, Forensic Investigation of Explosions, Second Edition, CRC Press, 1998.

[12] D.H. Fine, D. Lieb, F. Rufeh, Principle of operation of the thermal energy analyzer for the trace analysis of volatile and non-volatile n-nitroso compounds, J. Chromatogr. A 107 (1975) 351-357.

[13] J.M.F. Douse, Improved method for the trace analysis of explosives by silica capillary column gas chromatography with thermal energy analysis detection, J.Chromatogr. A 410 (1987) 181-189.

[14] P. Kolla, Trace analysis of explosives from complex mixtures with sample pretreatment and selective detection, J. Forensic Sci. 36 (1991) 1342-1359.

[15] J. Yinon, Forensic identification of explosives by mass spectrometry and allied techniques, Forensic Science Review 3 (1991) 18-27.

[16] J. Yinon, Forensic analysis of explosives by LC-MS, Forensic Sci. Rev.13 (2001) 19-28. 
[17] D. Perret, S. Marchese, A. Gentili, R. Curini, A. Terracciano, E. Bafile, F. Romolo, LC-MS-MS determination of stabilizers and explosives residues in hand-swabs, Chromatographia 68 (2008) 517524.

[18] L. Song, J.E. Bartmess, Liquid chromatography/negative ion atmospheric pressure photoionization mass spectrometry: a highly sensitive method for the analysis of organic explosives. Rapid Commun. Mass Spectrom. 23 (2009) 77-84.

[19] Y. Zhang, X. Ma, S. Zhang, C. Yang, Z. Ouyang, X. Zhang, Direct detection of explosives on solid surfaces by low temperature plasma desorption mass spectrometry. Analyst 134 (2009) 176-181.

[20] J. Becanova, Z. Friedl, Z. Simeka, Identification and determination of trinitrotoluenes and their degradation products using liquid chromatography-electrospray ionization mass spectrometry, Int. J. Mass Spectrometry 291 (2010) 133-139.

[21] F. Rowell, J. Seviour, A. Yimei Lim, C.G. Elumbaring-Salazar, J. Loke, J. Ma, Detection of nitroorganic and peroxide explosives in latent fingermarks by DART- and SALDI-TOF-mass spectrometry, Forensic Sci. Int. 221 (2012) 84-91.

[22] J. Almog, Forensic Science Does Not Start in the Lab: The Concept of Diagnostic Field Tests. J. Forensic Sci. 51 (2006) 1228-1234.

[23] T.F. Jenkins, M.E. Walsh, Development of field screening methods for TNT, 2,4-DNT and RDX in soil, Talanta 39 (1992) 419-428.

[24] A. Üzer, E. Erçă̆, R. Apak, Selective colorimetric determination of TNT partitioned between an alkaline solution and a strongly basic Dowex 1-X8 anion exchanger, Forensic Sci. Int. 174 (2008) 239243.

[25] M.E. Germain, M.J. Knapp, Optical explosives detection: from color changes to fluorescence turn-on, Chemical Society Reviews 38 (2009) 2543-2555.

[26] Y. Salinas, R. Martínez-Mánnez, M.D. Marcos, F. Sancenón, A.M. Costero, M. Parra, S. Gil, Optical chemosensors and reagents to detect explosives, Chemical Society Reviews 41 (2012) 1261-1296.

[27] R.G. Smith, N. D'Souza, S. Nicklin, A review of biosensors and biologically inspired systems for explosives detection, Analyst 133 (2008) 571-584.

[28] Yáñez-Sedeño, et al., Biosensors in forensic analysis. A review, Anal. Chim. Acta (2014), http://dx.doi.org/ 10.1016/j.aca.2014.03.011 Contents lists available at Science Direct Analytica Chimica Acta journal home page: www.e lsevier.com/loca te/aca

[29] Sensors 2014, 14, 4074-4085; doi:10.3390/s140304074 sensors ISSN 1424-8220 www.mdpi.com/journal/sensors Detection of Explosives in a Dynamic Marine Environment Using a Moored TNT Immunosensor P.T. Charles, A.A. Adams, J.R. Deschamps, S. Veitch, A. Hanson and A.W. Kusterbeck

[30] S. Girotti, S. Eremin, A. Montoya, M.J. Moreno, P. Caputo, M. D'Elia, L. Ripani, F.S. Romolo, E. Maiolini, Development of a chemiluminescent ELISA and a colloidal gold-based LFIA for TNT detection. Anal. Bioanal. Chem. 396 (2010) 687-695.

[31] M. Mirasoli, A. Buragina, L.S. Dolci, M. Guardigli, P. Simoni, A. Montoya, E. Maiolini, S. Girotti, A. Roda, Development of a chemiluminescence-based quantitative lateral flow immunoassay for on-field detection of 2,4,6-trinitrotoluene. Analytica Chimica Acta 721 (2012) 167- 172.

[32] D. Perret, S. Marchese, A. Gentili, R. Curini, A. Terracciano, E. Bafile, F.S. Romolo, LC-MS-MS Determination of Stabilizers and Explosives Residues in Hand-Swabs. Chromatographia 68 (2008) 517524.

[33] F.S. Romolo, L. Cassioli, S. Grossi, G. Cinelli, M.V. Russo, Surface-sampling and analysis of TATP by gas chromatography/mass spectrometry, Forensic Sci. Int. 224 (2013) 96-100.

[34] F.S. Romolo, Organic gunshot residue from leadfree ammunition. Romolo, F.S.; Série Criminalistique, XXIX, ISBN 2-940098-33-6, Lausanne, 2004. http://doc.rero.ch/lm.php?url=1000,40,5,20081009102309-IJ/These_Romolo.pdf 


\section{Acknowledgments}

This work was supported by grants from the Ministry of University and University of Bologna (PRIN 2006033429: "New Analytical Tools for Security and Criminal Investigations: Trace Detection and Identification of Explosives and Related Compounds") and "Fundamental Oriented Research", Bomb squad and forensic unit of Italian State Police for explosion tests. The authors are grateful to Samantha Connel for revising the manuscript. 


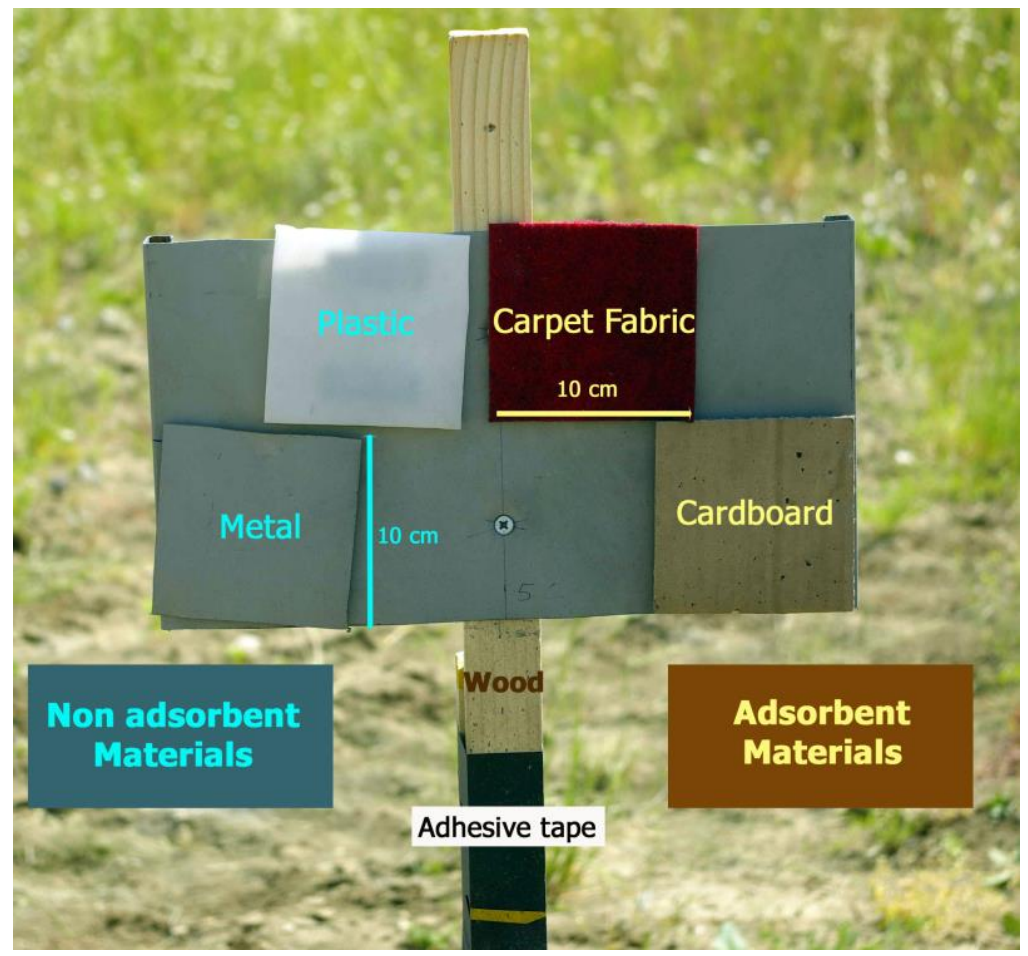

Figure 1 

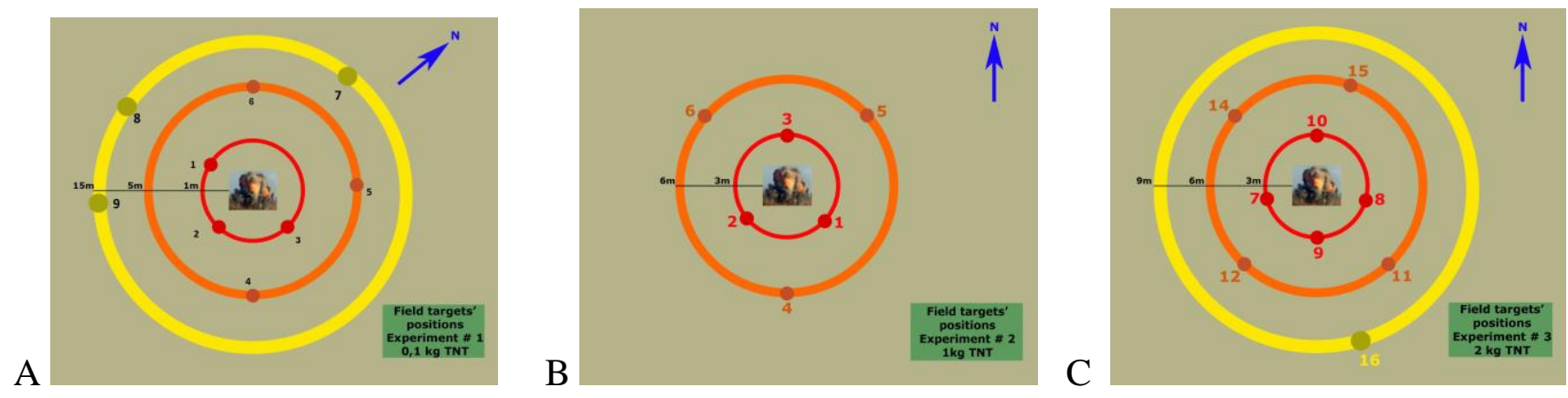

Figure 2 


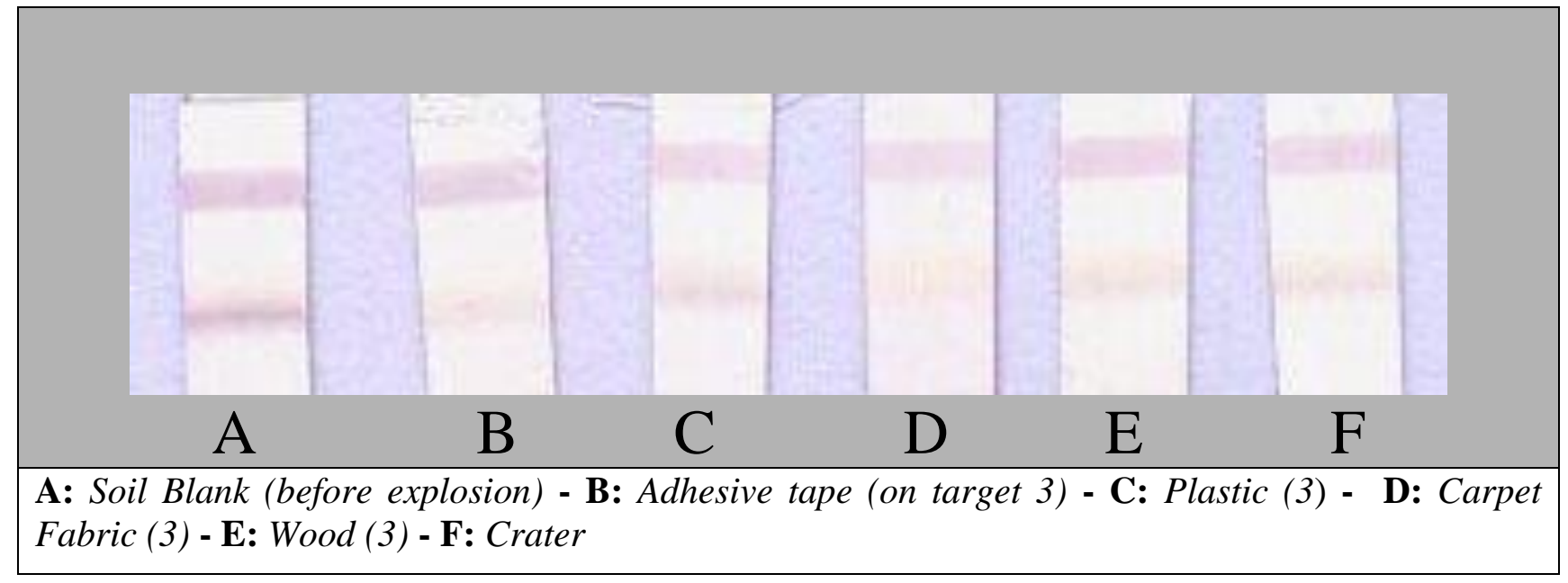

Figure 3 


\section{Figure captions}

Figure 1: Aspect and distribution of the materials compositing the targets employed during the explosion experiments

Figure 2: Distribution and distances of the targets in the $0,1 \mathrm{~kg}(\mathrm{~A}), 1 \mathrm{~kg}(\mathrm{~B})$, and $2 \mathrm{~kg}(\mathrm{C}) \mathrm{TNT}$ explosion experiments (images not scaled).

Figure 3: LFIA strips as they resulted after the analysis of positive samples from the $100 \mathrm{~g}$ TNT charge explosion test. 
Table 1. Data from the positive target samples after the explosion of $100 \mathrm{~g}$ charge of TNT. The remaining samples were negative.

\begin{tabular}{|c|c|c|c|}
\hline SAMPLE & $\begin{array}{c}\text { CL ELISA } \\
\left.\text { TNT(ng mL } \mathbf{~}^{-1}\right) \pm \mathbf{C V}(\%)\end{array}$ & $\begin{array}{c}\text { GC/MS } \\
\text { TNT }\left(n g \text { mL }^{-1}\right) \pm \operatorname{CV}(\%)\end{array}$ & LFIA(*) \\
\hline Adhesive tape & $141 \pm 11$ & $157 \pm 14$ & ++ \\
\hline Plexiglass & $57 \pm 8$ & $39 \pm 12$ & + \\
\hline Carpet fabric & $107 \pm-5$ & $122 \pm-15$ & ++ \\
\hline Wood & $40 \pm 18$ & $48 \pm 11$ & + \\
\hline Cardboard & $38 \pm 9$ & $46 \pm 9$ & \\
\hline $\begin{array}{lll}\text { Soil near the } \\
\text { target }\end{array}$ & $98 \pm 8$ & $123 \pm 14$ & + \\
\hline Soil (Blank) & Below LOD & Below LOD & \\
\hline
\end{tabular}

(*) + : positive sample; ++ clearly positive. 
Table 2: Results from the positive samples (targets 1, 2 and 3 and e soil collected close to the pole of target1) analyzed after the explosion of a $1 \mathrm{~kg}$ charge of TNT. All the remaining samples resulted negative when analyzed by all methods.

\begin{tabular}{|l|c|c|c|}
\hline SAMPLE & $\begin{array}{c}\text { CL ELISA } \\
\text { TNT }\left(\mathbf{n g} \mathbf{~ m L}^{-\mathbf{1}}\right) \pm \mathbf{C V}(\boldsymbol{\%})\end{array}$ & $\begin{array}{c}\text { GC/MS } \\
\text { TNT }\left(\mathbf{n g} \mathbf{~} L^{-\mathbf{1}}\right) \pm \mathbf{C V}(\boldsymbol{\%})\end{array}$ \\
\hline CARDBOARD 1 & $62 \pm 8$ & $55 \pm 9$ & + \\
\hline PLEXIGASS 1 & $27 \pm 10$ & $31 \pm 11$ & + \\
\hline TISSUE 1 & $46 \pm 9$ & $40 \pm 9$ & + \\
\hline WOOD 1 & $30 \pm 10$ & $25 \pm 8$ & + \\
\hline SOIL TARGET 1 & $23 \pm 10$ & $32 \pm 6$ & + \\
\hline CARDBOARD 2 & $33 \pm 10$ & $41 \pm 12$ & ++ \\
\hline PLEXIGASS 2 & $120 \pm 8$ & $136 \pm 11$ & + \\
\hline WOOD 3 & $32 \pm 10$ & $27 \pm 8$ & + \\
\hline TISSUE 3 & $24 \pm 9$ & $31 \pm 6$ & + \\
\hline
\end{tabular}

(*) + : positive sample; ++ clearly positive. 
Table 3. Results from samples collected from targets 7 and 8 and the soil taken close to the pole of the targets 7 and 8 after the explosion of a $2 \mathrm{~kg}$ charge of TNT. All the remaining samples resulted negative.

SAMPLE

CL ELISA

CL-LFIA

GC/MS

$\mathrm{TNT}\left(\mathrm{ng} \mathrm{mL} \mathrm{m}^{-1}\right) \pm \mathrm{CV}(\%) \quad \mathrm{TNT}(\mathrm{ng} \mathrm{mL}-1) \pm \mathrm{CV}(\%) \quad \mathrm{TNT}\left(\mathrm{ng} \mathrm{mL}^{-1}\right) \pm \mathrm{CV}(\%)$

$\begin{array}{cl}\text { CARDBOARD } 7 & 34 \pm 7 \\ \text { PLEXIGASS 7 } & 206 \pm 11 \\ \text { METAL 7 } & 200 \pm 14 \\ \text { TISSUE 7 } & 94 \pm 8 \\ \text { WOOD 7 } & 34 \pm 10 \\ \text { SOIL (Target7) } & 10 \pm 9 \\ \text { CARDBOARD 8 } & 23 \pm 10 \\ \text { SOIL (Target 8) } & 12 \pm 11\end{array}$

$39 \pm 8$

$199 \pm 13$

$180 \pm 18$

$111 \pm 18$

$28 \pm 11$

$4 \pm 7$

$19 \pm 12$

$19 \pm 14$

$$
\begin{aligned}
& 44 \pm 8 \\
& 200 \pm 14 \\
& 221 \pm 10 \\
& 122 \pm 8 \\
& 26 \pm 8 \\
& 18 \pm 12 \\
& 30 \pm 14 \\
& 21 \pm 10
\end{aligned}
$$


Table 4:. Results from handling tests, the CV values for these data were always lower than the $10 \%$.

\begin{tabular}{|c|c|c|c|c|c|c|c|c|c|c|c|c|}
\hline Samples & & CL-E & CISA & & & LFIA & & & & GC & & \\
\hline & HT1 & HT2 & HT3 & HT4 & HT1 & HT2 & HT3 & HT4 & HT1 & HT2 & HT3 & HT4 \\
\hline A, $1^{\text {st }}$ swab & 643 & 0 & 2 & 18 & ++ & - & + & + & 580 & 0.86 & 0.85 & 22 \\
\hline A, $2^{\text {nd }}$ swab & 212 & 4 & 0 & 3 & ++ & + & - & + & 187 & 1.1 & 0 & 1.1 \\
\hline $\begin{array}{l}\text { A, } 3^{\text {rd }} \text { swab } \\
1\end{array}$ & 47 & 0 & 0 & 1 & + & - & - & + & 11 & 0 & 0 & 0.84 \\
\hline B, $1^{\text {st }}$ swab & 52 & 3 & 3 & 1 & + & + & + & + & 67 & 0.88 & 0.89 & 0.89 \\
\hline $\mathbf{B}, 2^{\text {nd }}$ swab & 12 & 0 & 0 & 1 & + & - & - & + & 21 & 0.89 & 0 & 0.84 \\
\hline B, $3^{\text {rd }}$ swab & 0 & 0 & 1 & 0 & - & - & - & - & 0 & 0 & 0 & 0 \\
\hline C, $1^{\text {st }}$ swab & 128 & 2 & 2 & n.s* & ++ & + & + & n.s* & 147 & 0.91 & 0.85 & n.s* \\
\hline C, $2^{\text {nd }}$ swab & 30 & 1 & 0 & n.s ${ }^{*}$ & + & - & - & n.s* & 23 & 0 & 0 & n.s* \\
\hline C, $3^{\text {rd }}$ swab & 5 & 0 & 0 & n.s* & + & - & - & n.s* & 2.7 & 0 & 0 & n.s* \\
\hline
\end{tabular}

